\title{
Threshold of Body Temperature for the Initiation of Evaporative Thermoregulation in Swamp Buffaloes Abruptly Exposed to High Environmental Temperatures
}

\author{
Tateki Chikamune, Yukio Kanai, Hideya Homma, \\ Toleng ABdul-Latief and Naoto Ishikawa \\ Institute of Agriculture and Forestry, University of Tsukuba, \\ Tsukuba-shi Ibaraki-ken 305
}

(Received March 30, 1987)

\begin{abstract}
Key words : buffalo, thermoregulation, rectal temperature, respiratory volume, sweating rate
\end{abstract}

Body temperature of buffaloes is highly correlated with the seasonal and diurnal changes of air temperature, unlike in Holstein cattle ${ }^{1)}$. Furthermore, the stimulus of exposure to a high environmental temperature for the initiation of the thermoregulatory mechanism via both respiratory and body surface vaporization is less effective and the degree of body temperature lability is greater in buffaloes than in cattle ${ }^{2}$. Since active heat dissipation by respiratory and body surface vaporization is controlled by a thermostat-like mechanism located in the central nervous system ${ }^{3)}$, it was deemed interesting to determine the threshold of body core temperature at which such a evaporative cooling mechanism becomes active when buffaloes are abruptly exposed to high environmental temperatures.

\section{Materials and Methods}

Three buffalo-cows (body weight : 495-554 kg) with estimated ages ranging from 8 to 12 years were used in October at the Agricultural and Forestry Research Center, University of Tsukuba $\left(36^{\circ} \mathrm{N}\right)$, Ibaraki-Ken. All the animals were non-pregnant and dry.

The cows were initially kept in a barn where the air temperature and relative humidity ranged from 14 to $21^{\circ} \mathrm{C}\left(18.2^{\circ} \mathrm{C}\right.$ just before the transfer) and from 65 to $75 \%$, respectively, during 24 hours. They were then transferred abruptly to a climatic chamber at a fixed temperature of $35 \pm 2^{\circ} \mathrm{C}$ Relative humidity and light intensity in

高温度に曝した沼沢水牛の不感放熱体温調節反応開始体温 : 近宗干城・金井幸雄・本間秀弥・卜 レングーラティーフ・石川尚人（筑波大学, 茨城県 305) 
the chamber were $55-61 \%$, and $70-180$ lux $1 \mathrm{~m}$ above the floor, respectively.

The observations on rectal temperature, respiration rate, and respiratory volume were performed before exposure ( 0 time) and every 15 minutes during exposure for 4 hours. Sweating rates were determined every 30 minutes, simultaneously. The methods for the determination of these parameters were the same as those described in the previous report. The threshold of active respiratory cooling was defined as the rectal temperature at which an appreciable rise in the respiratory volume during 15 minutes exceeding by 5 times the mean value recorded during one hour before occurred and that the value did not decrease thereafter. Similarly, the threshold of sweating was defined as the rectal temperature at which an appreciable rise in the sweating rate during 30 minutes exceeding by 5 times that of the previous mean occurred and that the value did not decrease thereafter.
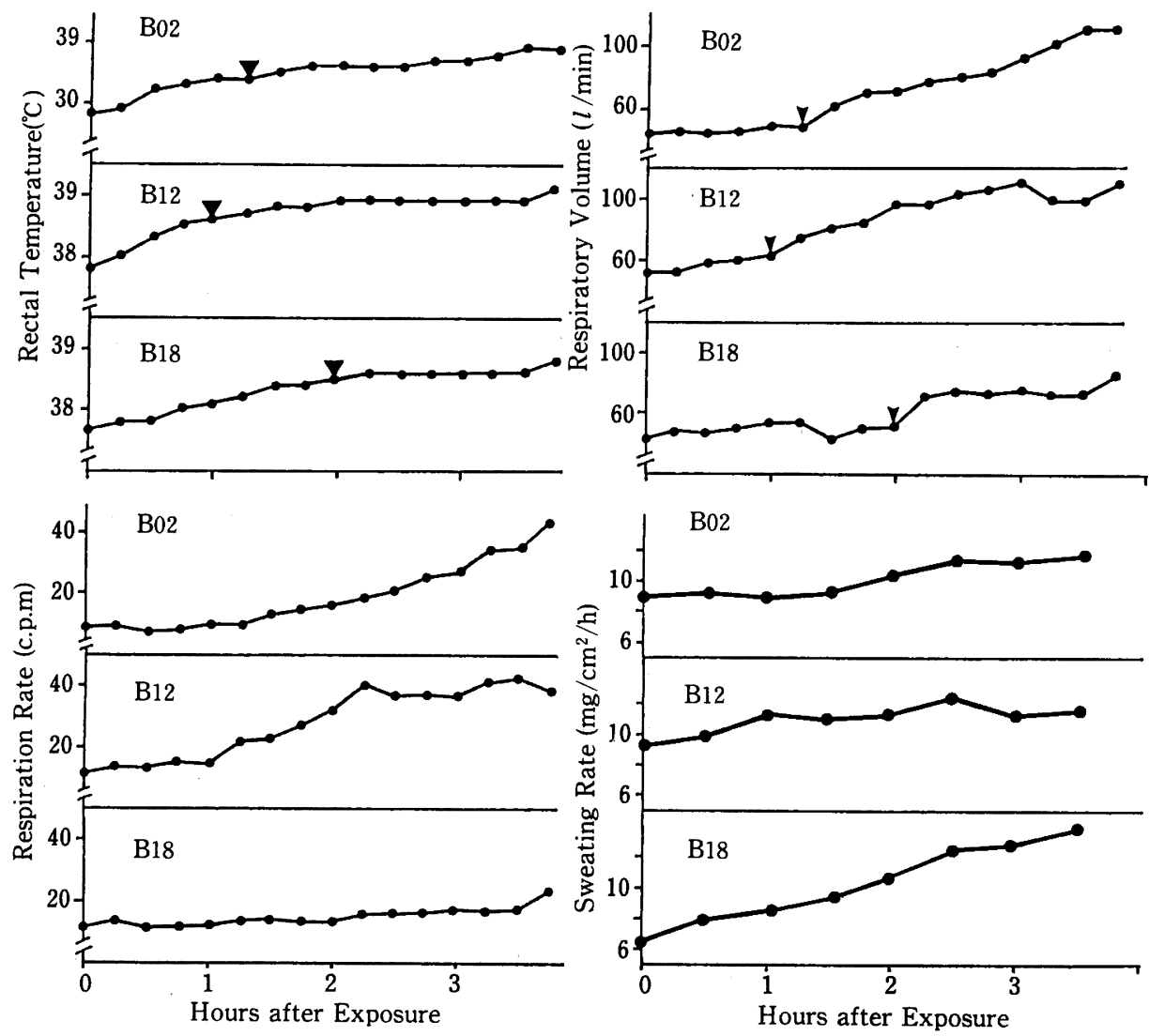

Fig. 1. Changes of the rectal temperature, respiration rate, respiratory volume and sweating rate in the three buffaloes (B 02, B 12 and B 18). $\boldsymbol{Y}$ : Onset of active respiratory cooling. $\nabla$ : Threshold of body temperature for the initiation of active respiratory cooling. 


\section{Results and Discussion}

Data on the changes of the rectal temperature, respiration rate, respiratory volume and sweating rate in each animal at the time of exposure to high environmental temperature are presented in Fig. 1.

The rectal temperature of the three buffaloes rose more steeply during the first one-third period than during the latter period, whereas the rate of increase in the respiratory volume together with the respiration rate was low during the first one or two hours. These results agreed with previous findings ${ }^{2)}$ in which no significant changes in the respiration rate and volume were observed in buffaloes during the $1.5 \mathrm{~h}$ exposure to a high environmental temperature of $35^{\circ} \mathrm{C}$.

In the present experiment, however, the respiratory volume began to rise thereafter abruptly. Thus based on the definition given above, the threshold of active respiratory cooling in each buffalo corresponded to a temperature of $38.4,38.6$ and $38.5^{\circ} \mathrm{C}$ (mean : $38.5^{\circ} \mathrm{C}$ ). These values are almost equivalent to the normal rectal temperature in cattle $^{2)}$, though if the buffaloes had been exposed to other environmental temperatures, the evaluation would have been different due to the possible interaction between the effects of heating for the skin and hypothalamus ${ }^{5)}$.

On the other hand, the threshold of the sweating based on the definition given above, could not be detected in spite of the gradual increase in the sweating rate of all the animals after $1.5 \mathrm{~h}$ of exposure to heat. These results may suggest an existence of different mechanisms in the control of respiratory evaporative cooling and that of sweating in this species.

It is concluded that the threshold of body temperature for the initiation of respiratory cooling in buffaloes stands far higher above their normal body temperature, which is presumably one of the main factors for the greater thermolability in this species compared with cattle.

\section{References}

1) Chikamune, T. and H.Shimizu, Indian J. Anim. Sci.,53 : 595-604. 1983.

2) Chikamune, T., Japn. J. Trop. Agr., 31: 6-11. 1987.

3) Whitrow, G.C., in Comparative Physiology of Thermoregulation Vol. II. (Whitrow, G.C. ed) 214-230. Academic Press. New York and London. 1971.

4) Chikamune, T., Y. Kanai, T. Ichikawa, H. Homma, K. Fukuda and H. Shimizu, Japn. J. Trop. Agr., 31 : 1-5. 1987.

5) Ingram, D.L. and G.C. Whittow, J. Physiol. (London) $163:$ 200-210. 